\title{
MTHFR 3'-untranslated region polymorphisms contribute to recurrent pregnancy loss risk and alterations in peripheral natural killer cell proportions
}

\author{
Eun Sun Kim', Jung Oh Kim¹, Hui Jeong An', Jung Hyun Sakong', Hyun Ah Lee', Ji Hyang Kim², Eun Hee Ahn², Young Ran Kim², \\ Woo Sik Lee ${ }^{3}$, Nam Keun Kim ${ }^{1}$ \\ 'Department of Biomedical Science, College of Life Science, CHA University, Seongnam; 'Department of Obstetrics and Gynecology, CHA Bundang \\ Medical Center, CHA University School of Medicine, Seongnam; ${ }^{3}$ Fertility Center of CHA Gangnam Medical Center, CHA University, Seoul, Korea
}

Objective: To identify the associations between polymorphisms of the 3'-untranslated region (UTR) of methylenetetrahydrofolate reductase (MTHFR) gene, which codes for an important regulatory enzyme primarily involved in folate metabolism, and idiopathic recurrent pregnancy loss (RPL) in Korean women.

Methods: The study population comprised 369 RPL patients and 228 controls. MTHFR 2572C > A, 4869C > G, 5488C > T, and 6685T > C 3'-UTR polymorphisms were genotyped by polymerase chain reaction-restriction fragment length polymorphism analysis or by TaqMan allelic discrimination assays. Natural killer cell proportions were determined by flow cytometry.

Results: The MTHFR 2572-5488-6685 (A-C-T) haplotype had an adjusted odds ratio of 0.420 (95\% confidence interval, $0.178-0.994 ; p=0.048$ ) for RPL. Analysis of variance revealed that MTHFR $4869 \mathrm{C}>\mathrm{G}$ was associated with altered CD56 $6^{+}$natural killer cell percentages (CC, $17.91 \% \pm 8.04 \% ; \mathrm{CG}, 12.67 \% \pm 4.64 \% ; p=0.024$ ) and folate levels (CC, $12.01 \pm 7.18 \mathrm{mg} / \mathrm{mL} ; \mathrm{CG}, 22.15 \pm 26.25 \mathrm{mg} / \mathrm{mL} ; p=0.006$ ).

Conclusion: Variants in the $3^{\prime}$-UTR of MTHFR are potential biomarkers for RPL. However, these results should be validated in additional studies of ethnically diverse groups of patients.

Keywords: 3’Untranslated regions; Korean; Methylenetetrahydrofolate reductase; Natural killer cells; Recurrent pregnancy loss; Women

\section{Introduction}

One in eight pregnant women will experience the loss of a pregnancy, most frequently within 2 to 3 months of conception [1]. The

Received: Mar 31, 2017· Revised: Jul 5, 2017· Accepted: Jul 5, 2017

Corresponding author: Nam Keun Kim

Department of Biomedical Science, College of Life Science, CHA University, 335 Pangyo-ro, Bundang-gu, Seongnam 13488, Korea

Tel: +82-31-780-5762 Fax:+82-31-780-5766 E-mail: nkkim@cha.ac.kr

*This work was partly supported by a grant of the Korea Healthcare Technology R\&D Project (HI15C1972010015), Ministry for Health, Welfare \& Family Affairs, Republic of Korea and by Basic Science Research Program through National Research Foundation of Korea Grants (2009-0093821, 2017R1D1A1B03031542 and 2015R1D1A1A09057432) funded by the Korean Government, Korea.

This is an Open Access article distributed under the terms of the Creative Commons Attribution Non-Commercial License (http://creativecommons.org/licenses/by-nc/4.0/) which permits unrestricted non-commercial use, distribution, and reproduction in any medium, provided the original work is properly cited. possibility of an additional pregnancy loss is $5 \%$ higher for women who experienced the loss of their first pregnancy [2]. There are many etiologic factors that contribute to recurrent pregnancy loss (RPL), defined by the American Society for Reproductive Medicine as the consecutive loss of two or more pregnancies $[3,4]$, including genetics, anatomical deformities, thrombophilia, endocrine dysfunction, placental anomalies, infection, smoking, excessive alcohol consumption, environmental factors, psychological trauma, and stress [5]. Recent studies investigating the pathophysiology of RPL have reported that a high level of homocysteine (Hcy) and a low level of folate in the blood might be a marker of RPL risk [6-8].

High levels of Hcy and/or a deficiency of folate in the plasma have been associated with reduced expression of the enzyme methylenetetrahydrofolate reductase (MTHFR), which catalyzes the conversion of 5, 10-methylenetetrahydrofolate to 5-methyltetrahydrofolate [9- 
12]. MTHFR is also a critical factor in DNA methylation and is an important regulatory enzyme primarily involved in folate metabolism $[13,14]$. A number of studies have examined the association of RPL incidence with MTHFR polymorphisms, such as 677C > T (rs1801133) and 1298A >C (rs1801131) [15,16]. The MTHFR 677T allele was closely correlated with decreased MTHFR activity, resulting in folate deficiency and increased plasma Hcy levels [11]. Furthermore, the 677T allele was determined to be a potential genetic risk factor for increased RPL susceptibility in recent meta-analyses [17]. Although an association between RPL and genetic variation of the 3 '-untranslated region (UTR) of MTHFR has been reported [18], such variants and their associations with RPL have not been studied in detail [19]. Variations in the 3'-UTR may result in the inhibition of translation or degradation of mRNA [20], thereby altering the expression of the encoded protein. This study examined the $2572 \mathrm{C}>\mathrm{A}$ (rs4846049), $4869 \mathrm{C}>\mathrm{G}(\mathrm{rs} 1537514), 5488 \mathrm{C}>\mathrm{T}(\mathrm{rs3737967)})$, and 6685T $>C$ (rs4846048) polymorphisms of MTHFR in pregnant women and their association with RPL.

Studies of patients with idiopathic RPL and in vitro fertilization-embryo transfer failure have shown that the numbers of decidual natural killer (NK) cells are significantly reduced in those patients [21,22], indicating their importance during pregnancy [23]. In particular, the accumulation of $\mathrm{CD} 56^{+}$subsets of NK cells has been shown to be important during early pregnancy $[24,25]$. As such, we also examined the numbers of NK cells and the proportions of CD56 subtypes in pregnant women and those with RPL in relation to their MTHFR genotype.

\section{Methods}

\section{Study population}

For this study, 369 women with RPL and 228 controls were recruited from the CHA Bundang Medical Center. Written consent was obtained from all participants. The women included in the control group had a history of at least 1 successful naturally conceived pregnancy, no history of pregnancy loss, and a karyotype of $46, X X$. The use of participants in this study was approved under institutional review board (No. BD2010-123D).

RPL patients were defined as those who had experienced at least two consecutive spontaneous abortions identified by ultrasonography, human chorionic gonadotropin levels, and/or physical examinations. Patients with a history of smoking or alcohol use were excluded from the study. RPLs resulting from anatomic abnormalities, such as intrauterine adhesions, septate uteri, and uterine fibroids, were determined by hysterosalpingography, hysteroscopy, computed tomography, and magnetic resonance imaging. Hormonal causes of miscarriages included hyperprolactinemia, luteal insufficiency, and thyroid disease, and were determined from the blood levels of the appropriate hormones. To verify a chromosomal cause for miscarriage, chromosome analysis was performed using standard protocols [26], and metaphase chromosomes were examined using the trypsin-Giemsa banding (GTG-banding) method. Bacterial cultures for Ureaplasma urealyticum and/or Mycoplasma hominis were used to identify miscarriages caused by infection. Autoimmune causes of RPL, defined as antiphospholipid syndrome and lupus, were evaluated using lupus anticoagulant and anticardiolipin antibodies. Thrombophilia, determined by deficiencies of protein $C$ and protein $S$ and the presence of anti- $\beta$ - 2 glycoprotein antibodies, was also considered as a cause of RPL.

\section{Genotyping}

Genomic DNA samples from RPL patients and controls were extracted from anticoagulated peripheral blood using the G-DEX blood extraction kit (Intron, Seongnam, Korea). MTHFR 2572C >A and MTHFR $4869 \mathrm{C}>\mathrm{G}$ polymorphisms were genotyped by polymerase chain reaction-restriction fragment length polymorphism analysis using the following primers: $5^{\prime}$-TTG CCA ACT AAG CCC TCG AAA CAA3' (sense) and 5'-TGC CAC ATC TCT TCT ACG ATG CCA-3' (antisense) for MTHFR 2572C >A, and 5'-TCC AGC CCT GAG CCC AGA GTC T-3' (sense) and 5'-AGG CAA GCC CCT CAG CCCTT-3' (antisense) for MTH$F R 4869 C>G$. Restriction enzyme digestions, using Styl and BsmAl (New England BioLabs, Essex County, MA, USA), were performed for the MTHFR 2572C > A and MTHFR 4869C > G polymorphisms, respectively, at $37^{\circ} \mathrm{C}$ for 16 hours.

MTHFR 5488C > T and MTHFR 6685T > C polymorphisms were assessed using real-time polymerase chain reaction (RG-6000; Corbett Research, Mortlake, Australia) with the following primers and probes: 5'-GAG GCA CCA GCT CTG TGG-3' (forward) and 5'-CCC CAG GAA GTC CAA GC-3' (reverse) with 5'-FAM-CAG CAG CTG CGG GTC TGA A-TAMRA-3' (C allele) and 5' JOE-CAG CAG CTG TGG GTC TGA A-TAMRA-3' (T allele) for MTHFR 5488C > T, and 5'-CCA GAC CAG AAG CAG TTA-3' (forward) and 5'-GCT GTG CAG TGT CAT TT-3' (reverse) with 5'-FAMCAC CAA CAA ATG GTG ATA AG-TAMRA-3' (T allele) and 5'-JOE-CAC CAA CAA GTG GTG ATA AG-TAMRA-3' (C allele) for MTHFR 6685T > C.

\section{Estimations of clinical characteristics from blood samples}

Levels of Hcy, folate, total cholesterol, and uric acid were measured in plasma samples collected from RPL patients after 12 hours of fasting. Hcy was measured using a fluorescence polarization immunoassay with an Abbott IMx analyzer (Abbott Laboratories, Abbott Park, IL, USA). The total cholesterol levels and uric acid concentrations were estimated using commercially available enzymatic colorimetric tests by the Roche/Hitachi Modular Pre-analytics Plus system (Roche Diagnostics, Mannheim, Germany). Additionally, platelet counts, folate and plasminogen activator inhibitor-1 levels, prothrombin time, 
and activated partial thromboplastin time (aPTT) were determined.

\section{Estimation of peripheral CD56 ${ }^{+} \mathrm{NK}$ cell proportions}

Measurements of NK cells were performed by flow cytometry with CellQuest software (BD FACSCalibur; BD Biosciences, Seoul, Korea). Fluorescently labeled (fluorescein isothiocyanate, phycoerythrin [PE], peridinin chlorophyll protein, and allophycocyanin) monoclonal antibodies specific for $C D 3, C D 16$, and CD56 were purchased from BD Biosciences. Anti-NKG2A-PE antibodies were obtained from Immunotech (Beckman Coulter, Fullerton, CA, USA). Peripheral blood mononuclear cells $\left(2.5 \times 10^{5}\right)$ were stained for cell-surface antigen expression at $4^{\circ} \mathrm{C}$ in the dark for 30 minutes, washed twice in $2 \mathrm{~mL}$ of phosphate-buffered saline containing $1 \%$ bovine serum albumin and $0.01 \%$ sodium azide (FACS wash buffer), and subsequently fixed in $200 \mu \mathrm{L}$ of a $1 \%$ formaldehyde solution (Sigma-Aldrich, St. Louis, MO, USA) prior to sorting, as previously described $[27,28]$.

\section{Statistical analysis}

The associations between MTHFR polymorphisms and RPL risk were examined by odds ratios (ORs), adjusted odds ratios (AORs), and 95\% confidence intervals (Cls). The data are presented as the mean numbers and percentages with standard deviations (categorical variables). Differences in the frequencies of MTHFR polymorphisms between the control and patient groups were assessed using the Fisher exact test and a logistic regression model. Statistical significance was accepted at $p<0.05$. The correlations of each genotype or allele with the proportion of NK cells and plasma Hcy, folate, total cholesterol, and uric acid levels were assessed by the Kruskal-Wallis and Mann-Whitney $\mathrm{U}$ tests. Statistical analyses were performed using GraphPad Prism 4.0 (GraphPad Software Inc., San Diego, CA, USA), MedCalc version 12.1.4 (MedCalc Software, Mariakerke, Belgium), and StatsDirect V2.6.6 (StatsDirect Ltd., Warrington, UK). Haplotype analysis was performed using SNPAlyze ver. 5.1 (Dynacom Co., Yokohama, Japan), Hapstat 3.0 (http://dlin.web.unc.edu/software/hapstat), and Haploview (https:// www.broadinstitute.org/haploview/haploview).

\section{Results}

The clinical characteristics of the RPL patients and control subjects are presented in Table 1. The MTHFR genotype frequencies for controls and RPL patients were consistent with expectations under the assumption of Hardy-Weinberg equilibrium (Table 2). We further stratified the MTHFR polymorphism data among RPL patients with three or more pregnancy losses and those with four or more (Supplement 1). The genotypes were not associated with RPL. However, haplotype analyses for multiple MTHFR 3'-UTR polymorphisms revealed a negative correlation between RPL and the MTHFR 2572/
Table 1. Clinical profiles of control subjects and RPL patients

\begin{tabular}{lccc}
\hline Characteristics & Control $(\mathrm{n}=228)$ & $\mathrm{RPL}(\mathrm{n}=369)$ & $p$-value \\
\hline Age $(\mathrm{yr})$ & $32.84 \pm 4.12$ & $32.84 \pm 4.23$ & 0.668 \\
BMI $\left(\mathrm{kg} / \mathrm{m}^{2}\right)$ & $21.64 \pm 3.41$ & $21.47 \pm 3.89$ & 0.116 \\
Previous pregnancy loss & $\mathrm{NA}$ & $3.03 \pm 1.54$ & \\
RPL $<14$ wk (\%) & $\mathrm{NA}$ & 98.84 & \\
Live birth & $1.72 \pm 0.59$ & $\mathrm{NA}$ & \\
Mean gestational age $(\mathrm{wk})$ & $39.17 \pm 1.63$ & $7.36 \pm 1.95$ & $<0.001$ \\
Homocysteine $(\mathrm{mmol} / \mathrm{L})$ & $\mathrm{NA}$ & $6.95 \pm 2.12$ & \\
Folate $(\mathrm{mg} / \mathrm{mL})$ & $\mathrm{NA}$ & $13.96 \pm 11.89$ & \\
Total cholesterol $(\mathrm{mg} / \mathrm{dL})$ & $\mathrm{NA}$ & $187.20 \pm 49.57$ & \\
Uric acid $(\mathrm{mg} / \mathrm{dL})$ & $\mathrm{NA}$ & $3.79 \pm 0.85$ & \\
CD56 ${ }^{+} \mathrm{NK}$ cell $(\%)$ & $\mathrm{NA}$ & $18.05 \pm 8.01$ & \\
PAl- $1(\mathrm{ng} / \mathrm{mL})$ & $\mathrm{NA}$ & $10.45 \pm 5.72$ & \\
PLT $\left(10^{3} / \mathrm{mL}\right)$ & $\mathrm{NA}$ & $255.24 \pm 57.88$ & \\
PT $(\mathrm{sec})$ & $\mathrm{NA}$ & $11.60 \pm 0.87$ & \\
\hline
\end{tabular}

Values are presented as mean \pm standard deviation.

RPL, recurrent pregnancy loss; BMI, body mass index; NA, not available; NK, natural killer; PAI-1, plasminogen activator inhibitor-1; PLT, platelet count; PT, prothrombin time.

5488/6685 model, in particular, with the A-C-T alleles $(p=0.048)$ (Table 3). In addition, we conducted a haplotype analysis based on our previous studies to investigate the association of the well-known MTHFR 677C > T/1298A > C mutations with MTHFR 3'-UTR polymorphisms (Supplement 2), which showed that RPL was negatively correlated with the MTHFR 677-1298-1793-2572-4869-5488-6685 model, particularly, with C-C-G-A-C-C-T (OR, 0.026; 95\% Cl, 0.002-0.446; $p<0.001)$. A significant association was also found with MTHFR 257 $2 \mathrm{CC} / 6685 \mathrm{CT}$ (AOR, 2.867; 95\% Cl, 1.068-7.696; $p=0.037$ ) in a combination analysis (Supplement 3 ). However, there were no associations with RPL or other genotypic combinations.

We conducted variance analyses for differences in clinical factors and genotypes in RPL patients (Figure 1, Supplements 4 and 5). We investigated the $\mathrm{CD}^{2} 6^{+} \mathrm{NK}$ cell proportions and plasma levels of $\mathrm{Hcy}$, folate, total cholesterol, and uric acid, as well as blood coagulation factors such as prothrombin time, plasminogen activator inhibitor-1, platelet count, and aPTT. The percentages of $\mathrm{CD}^{+} 6^{+} \mathrm{NK}$ cells and folate levels were significantly different between the alleles of MTHFR 4869 in RPL patients with three or more lost pregnancies ( $p=0.024$ and $p=0.006$, respectively) (Figure 1, Supplement 5), with a similar trend observed in women with the MTHFR 4869CG genotype and three or more lost pregnancies (Supplement 4).

The MTHFR $4869 \mathrm{C}>\mathrm{G}$ polymorphism was also associated with plasma Hcy and folate levels (Supplement 6 ) and with $\mathrm{CD}^{2} 6^{+} \mathrm{NK}$ cell proportions and aPTT (Supplement 7) after adjusting for the ages of the participants. The age-adjusted analyses also revealed associations between the MTHFR 5488C > T dominant genotype and plasma Hcy, folate levels, and aPTT, as well as associations between the MTH- 
Table 2. Frequencies of MTHFR 3'-UTR polymorphisms in control subjects and RPL patients

\begin{tabular}{|c|c|c|c|c|c|}
\hline Genotype & Control $(n=228)$ & $\operatorname{RPL}(n=369)$ & AOR $(95 \% \mathrm{Cl})$ & $p$-value & FDR-p \\
\hline \multicolumn{6}{|l|}{ MTHFR $2572 C>A$} \\
\hline $\mathrm{CC}$ & $142(62.3)$ & $252(68.3)$ & 1.000 (reference) & & \\
\hline CA & $78(34.2)$ & $111(30.1)$ & $0.800(0.561-1.142)$ & 0.220 & 0.419 \\
\hline AA & $8(3.5)$ & $6(1.6)$ & $0.425(0.144-1.250)$ & 0.120 & 0.600 \\
\hline Dominant (CC vs. CA+AA) & & & $0.766(0.542-1.083)$ & 0.132 & 0.457 \\
\hline Recessive $(C C+C A$ vs. $A A)$ & & & $0.455(0.156-1.327)$ & 0.149 & 0.745 \\
\hline HWE- $p$ & 0.494 & 0.111 & & & \\
\hline \multicolumn{6}{|l|}{ MTHFR $4869 \mathrm{C}>\mathrm{G}$} \\
\hline $\mathrm{CC}$ & $190(83.3)$ & $317(85.9)$ & 1.000 (reference) & & \\
\hline CG & $37(16.2)$ & $51(13.8)$ & $0.826(0.521-1.308)$ & 0.415 & 0.419 \\
\hline GG & $1(0.4)$ & $1(0.3)$ & $0.586(0.036-9.501)$ & 0.707 & 0.881 \\
\hline Dominant (CC vs. CG+GG) & & & $0.820(0.520-1.293)$ & 0.393 & 0.457 \\
\hline Recessive (CC+CG vs. GG) & & & $0.614(0.038-9.942)$ & 0.732 & 0.869 \\
\hline HWE- $p$ & 0.571 & 0.481 & & & \\
\hline \multicolumn{6}{|l|}{ MTHFR 5488C > T } \\
\hline CC & $177(77.6)$ & $298(80.8)$ & 1.000 (reference) & & \\
\hline CT & $49(21.5)$ & $67(18.2)$ & $0.812(0.537-1.226)$ & 0.322 & 0.419 \\
\hline$\pi$ & $2(0.9)$ & $4(1.1)$ & $1.209(0.219-6.688)$ & 0.828 & 0.881 \\
\hline Dominant (CC vs. CT+TT) & & & $0.827(0.551-1.240)$ & 0.357 & 0.457 \\
\hline Recessive (CC+CT vs. TT) & & & $1.238(0.224-6.832)$ & 0.806 & 0.869 \\
\hline HWE- $p$ & 0.486 & 0.914 & & & \\
\hline \multicolumn{6}{|l|}{ MTHFR 6685T>C } \\
\hline$\pi$ & $182(79.8)$ & $285(77.2)$ & 1.000 (reference) & & \\
\hline $\mathrm{TC}$ & $43(18.9)$ & $80(21.7)$ & $1.187(0.784-1.797)$ & 0.419 & 0.419 \\
\hline $\mathrm{CC}$ & $3(1.3)$ & $4(1.1)$ & $0.891(0.196-4.056)$ & 0.881 & 0.881 \\
\hline Dominant (TT vs. TC+CC) & & & $1.166(0.778-1.749)$ & 0.457 & 0.457 \\
\hline Recessive (TT+TC vs. CC) & & & $0.820(0.181-3.715)$ & 0.797 & 0.869 \\
\hline HWE- $p$ & 0.800 & 0.537 & & & \\
\hline
\end{tabular}

Values are presented as number (\%).

MTHFR, methylenetetrahydrofolate reductase; UTR, untranslated region; RPL, recurrent pregnancy loss; AOR, adjusted odds ratio (adjusted by age of participants); $\mathrm{Cl}$, confidence interval; FDR- $p$, false discovery rate-adjusted $p$-value; HWE- $p$, Hardy-Weinberg equilibrium $p$-value.

FR 6685T > C dominant genotype and plasminogen activator inhibitor-1 levels and aPTT (Supplements 6, 7).

\section{Discussion}

In this study, we investigated four 3'-UTR polymorphisms of the MTH$F R$ gene in relation to the occurrence of RPL. We found that the $2572 C$ $>\mathrm{A}, 4869 \mathrm{C}>\mathrm{G}, 5488 \mathrm{C}>\mathrm{T}$, and $6685 \mathrm{~T}>\mathrm{C}$ MTHFR genotypes were substantially associated with RPL susceptibility and displayed significant haplotype and environmental factor effects (occupational exposure, air pollution, etc.). Specifically, MTHFR $4869 \mathrm{C}>\mathrm{G}$ and $5488 \mathrm{C}>\mathrm{T}$ polymorphisms were associated with increased $\mathrm{Hcy}$ levels and decreased folate levels in plasma. To our knowledge, this is the first study to provide evidence linking 3'-UTR polymorphisms of MTHFR with RPL. Combined with previous findings linking MTHFR polymorphisms with increased RPL susceptibility [15-17], our data implicate genetic variation in the 3'UTR, further supporting the role of MTHFR in RPL.
Previous studies have reported haplotype analysis of MTHFR $677 \mathrm{C}$ $>T$ and 1298A $>C$ C $[6,11,12,14,16,17]$, but the single nucleotide polymorphisms (SNPs) present in the 3'-UTR have not been analyzed. These additional SNPs may alter MTHFR expression or function, as was found with MTHFR 677C > T SNPs with regard to RPL. Moreover, newly identified SNPs may be useful as biomarkers. For these reasons, we conducted a study to examine the SNP genotypes and haplotypes of the 3'-UTR region, which is the microRNA (miRNA) binding site. We found that RPL was associated with higher frequencies of the 4869G and 5488T MTHFR alleles. These alleles were, in turn, associated with differences in Hcy and folate levels between controls and women with RPL. Furthermore, the MTHFR 4869G allele was associated with lower percentages of $\mathrm{CD} 56^{+} \mathrm{NK}$ cells, which has been linked with a favorable pregnancy result in women with RPL [29]. The activation of NK cells is an important stage in the inflammatory response and is known as a prognostic factor in women with RPL [30]. Interestingly, the frequency of the MTHFR $4869 \mathrm{C}>\mathrm{G}$ polymorphism tended to de- 
Table 3. Haplotype analysis of MTHFR 3'-UTR polymorphisms control subjects and RPL patients

\begin{tabular}{|c|c|c|c|c|c|}
\hline Haplotype & Control $(2 n=456)$ & $\operatorname{RPL}(2 n=738)$ & OR $(95 \% \mathrm{Cl})$ & $p$-value ${ }^{a)}$ & FDR- $p$ \\
\hline C-C-C-T & 0.758 & 0.772 & 1.000 (reference) & & \\
\hline C-C-T-T & 0.013 & 0.016 & $1.214(0.451-3.265)$ & 0.809 & 0.967 \\
\hline C-C-T-C & 0.000 & 0.002 & $1.822(0.074-44.89)$ & 1.000 & 1.000 \\
\hline C-G-C-T & 0.000 & 0.002 & $1.822(0.074-44.89)$ & 1.000 & 1.000 \\
\hline A-C-C-T & 0.025 & 0.012 & $0.455(0.190-1.092)$ & 0.109 & 0.709 \\
\hline$A-C-C-C$ & 0.075 & 0.072 & $0.946(0.603-1.485)$ & 0.818 & 0.967 \\
\hline A-C-T-T & 0.020 & 0.013 & $0.607(0.239-1.544)$ & 0.330 & 0.766 \\
\hline A-C-T-C & 0.000 & 0.003 & $3.037(0.145-63.49)$ & 0.530 & 0.766 \\
\hline A-G-C-T & 0.002 & 0.000 & $0.203(0.008-4.988)$ & 0.378 & 0.766 \\
\hline A-G-C-C & 0.000 & 0.003 & $3.037(0.145-63.49)$ & 0.530 & 0.766 \\
\hline C-C-T & 0.771 & 0.788 & 1.000 (reference) & & \\
\hline A-C-T & 0.045 & 0.024 & $0.519(0.273-0.988)$ & 0.063 & 0.378 \\
\hline \multicolumn{6}{|c|}{ MTHFR 2572-5488-6685 } \\
\hline C-C-T & 0.758 & 0.773 & 1.000 (reference) & & \\
\hline A-C-T & 0.028 & 0.012 & $0.420(0.178-0.994)$ & 0.048 & 0.336 \\
\hline \multicolumn{6}{|c|}{ MTHFR 4869-5488-6685 } \\
\hline C-C-T & 0.782 & 0.781 & 1.000 (reference) & & \\
\hline G-T-C & 0.008 & 0.000 & $0.069(0.004-1.282)$ & 0.022 & 0.154 \\
\hline \multicolumn{6}{|c|}{ MTHFR 4869-6685 } \\
\hline C-T & 0.815 & 0.809 & 1.000 (reference) & & \\
\hline $\mathrm{G}-\mathrm{C}$ & 0.008 & 0.000 & $0.069(0.004-1.291)$ & 0.022 & 0.066 \\
\hline
\end{tabular}

MTHFR, methylenetetrahydrofolate reductase; UTR, untranslated region; RPL, recurrent pregnancy loss; OR, odds ratio; $\mathrm{Cl}$, confidence interval; FDR-p, false discovery rate-adjusted $p$-value.

a)Fisher exact test.
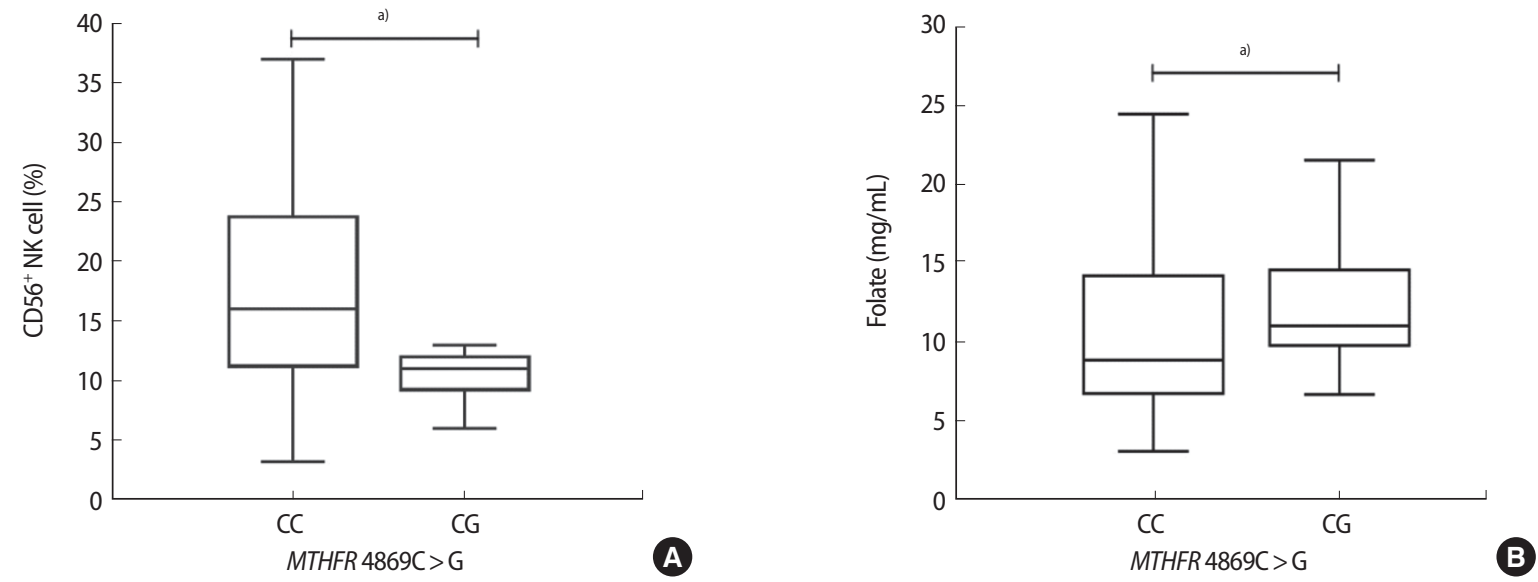

Figure 1. The MTHFR $4869 \mathrm{C}>\mathrm{G}$ polymorphism is associated with differences in $\mathrm{CD} 56^{+} \mathrm{NK}$ cell percentages and folate levels in women with recurrent pregnancy loss. Statistical analyses were performed using the Kruskal-Wallis test for the MTHFR $4869 \mathrm{C}>\mathrm{G}$ genotype and the percentages of CD56 NK cells (A) and folate levels (B) in women with three or more lost pregnancies. NK, natural killer; MTHFR, methylenetetrahydrofolate reductase. al $p<0.05$. 
crease with an increasing number of lost pregnancies. Therefore, our study demonstrated a negative correlation between the MTHFR $4869 \mathrm{G}$ allele frequency and $\mathrm{CD} 56^{+} \mathrm{NK}$ cell proportion, indicating that the presence of this allele can impact the activity of $\mathrm{CD}^{+} \mathrm{NK}$ cells.

In a previous study, the proportion of NK cells, depending on the MTHFR 677C > T polymorphism, was associated with an increased risk of RPL [16]. Similarly, we found that the proportion of NK cells was lower with MTHFR 4869CG than with MTHFR 4869CC. Therefore, the decrease in NK cells, which influence immune balance during pregnancy, was associated with RPL occurrence. Our results also indicated that the MTHFR $4869 \mathrm{C}>\mathrm{G}$ polymorphism may be somewhat protective against $R P L$, although the difference was not statistically significant. However, the haplotypes with the MTHFR 4869G allele were significantly associated with a lower risk of RPL occurrence. Furthermore, we also found that the frequency of the MTHFR 2572A allele was lower in women with higher numbers of lost pregnancies, indicating that Korean women with this polymorphism are more susceptible to RPL.

Although the functional impacts of these genetic variations in the 3'-UTR region are not fully understood, these polymorphisms may alter miRNA binding affinities and affect the translation or stability of the MTHFR transcript [19]. For example, the MTHFR 2572C > A variant is associated with increased binding of miR-149 and reduced MTHFR expression [31]. Further studies of the effects of the other MTHFR 3'UTR polymorphisms are needed to determine their effect on miRNA binding and MTHFR expression.

Several limitations of this study should be noted. First, this study did not control for additional environmental risk factors for RPL that may have influenced the results. Second, the study population was limited to Koreans, and our findings may therefore not be applicable to other populations. Lastly, the number of patients included in the subgroup analysis was relatively small.

In conclusion, this study examined four polymorphisms of the 3'UTR of MTHFR in association with RPL prevalence in Korean women. We found that the MTHFR 4869C $>G$ polymorphism was associated with lower percentages of $\mathrm{CD} 56^{+} \mathrm{NK}$ cells and higher folate levels in women with RPL. Therefore, variants in the 3'-UTR of MTHFR in women may represent potential biomarkers of RPL. However, additional studies of ethnically diverse groups of patients are needed to validate these findings.

\section{Conflict of interest}

No potential conflict of interest relevant to this article was reported.

\section{Supplementary materials}

Supplement 1. Frequencies of MTHFR gene polymorphisms accord- ing to the number of pregnancy losses. Supplemental data can be found at: http://ecerm.org/src/sm/cerm-44-152-s001.pdf.

Supplement 2. Haplotype analysis of MTHFR gene polymorphisms in control subjects and RPL patients. Supplemental data can be found at: http://ecerm.org/src/sm/cerm-44-152-s002.pdf.

Supplement 3. Combined analysis of MTHFR gene polymorphisms in control subjects and RPL patients. Supplemental data can be found at: $h$ ttp://ecerm.org/src/sm/cerm-44-152-s003.pdf.

Supplement 4. Clinical parameters according to MTHFR gene polymorphisms for patients with two or more lost pregnancies. Supplemental data can be found at: http://ecerm.org/src/sm/cerm-44152-s004.pdf.

Supplement 5. Clinical parameters according to MTHFR gene polymorphisms for patients with three or more lost pregnancies. Supplemental data can be found at: http://ecerm.org/src/sm/cerm-44152-s005.pdf.

Supplement 6. Genetic associations between MTHFR gene polymorphisms and homocysteine and folate with adjustment for age. Supplemental data can be found at: http://ecerm.org/src/sm/cerm44-152-s006.pdf.

Supplement 7. Associations of MTHFR gene polymorphisms with $\mathrm{CD} 56^{+} \mathrm{NK}$ cells, PAI-1, and aPTT with adjustment for age. Supplemental data can be found at: http://ecerm.org/src/sm/cerm-44-152-s007.pdf.

\section{References}

1. Wilcox AJ, Weinberg CR, O'Connor JF, Baird DD, Schlatterer JP, Canfield RE, et al. Incidence of early loss of pregnancy. N Engl J Med 1988;319:189-94.

2. Sierra S, Stephenson M. Genetics of recurrent pregnancy loss. Semin Reprod Med 2006;24:17-24.

3. Coulam CB, Clark DA, Beer AE, Kutteh WH, Silver R, Kwak J, et al. Current clinical options for diagnosis and treatment of recurrent spontaneous abortion: Clinical Guidelines Recommendation Committee for Diagnosis and Treatment of Recurrent Spontaneous Abortion. Am J Reprod Immunol 1997;38:57-74.

4. Practice Committee of American Society for Reproductive Medicine. Definitions of infertility and recurrent pregnancy loss: a committee opinion. Fertil Steril 2013;99:63.

5. Choi YS, Kwon H, Kim JH, Shin JE, Choi Y, Yoon TK, et al. Haplotypebased association of ACE I/D, AT1R 1166A>C, and AGT M235T polymorphisms in renin-angiotensin-aldosterone system genes in Korean women with idiopathic recurrent spontaneous abortions. Eur J Obstet Gynecol Reprod Biol 2011;158: 225-8.

6. Puri M, Kaur L, Walia GK, Mukhopadhhyay R, Sachdeva MP, Trivedi SS, et al. MTHFR C677T polymorphism, folate, vitamin B12 and homocysteine in recurrent pregnancy losses: a case control 
study among North Indian women. J Perinat Med 2013;41:54954.

7. Nelen WL, Blom HJ, Steegers EA, den Heijer M, Eskes TK. Hyperhomocysteinemia and recurrent early pregnancy loss: a metaanalysis. Fertil Steril 2000;74:1196-9.

8. Ozkan Y, Yardim-Akaydin S, Erdem A, Simsek B. Variability of total thiol compounds, oxidative and nitrosative stress in uncomplicated pregnant women and nonpregnant women. Arch Gynecol Obstet 2012;285:1319-24.

9. Goyette P, Sumner JS, Milos R, Duncan AM, Rosenblatt DS, Matthews RG, et al. Human methylenetetrahydrofolate reductase: isolation of CDNA mapping and mutation identification. Nat Genet 1994;7:551.

10. An X, Hou J, Gao T, Lei Y, Li G, Song Y, et al. Single-nucleotide polymorphisms g.151435C $>$ T and g.173057T >C in PRLR gene regulated by bta-miR-302a are associated with litter size in goats. Theriogenology 2015;83:1477-83.e1.

11. van der Put NM, Gabreels F, Stevens EM, Smeitink JA, Trijbels FJ, Eskes TK, et al. A second common mutation in the methylenetetrahydrofolate reductase gene: an additional risk factor for neural-tube defects? Am J Hum Genet 1998;62:1044-51.

12. Naushad SM, Krishnaprasad C, Devi AR. Adaptive developmental plasticity in methylene tetrahydrofolate reductase (MTHFR) C677T polymorphism limits its frequency in South Indians. Mol Biol Rep 2014;41:3045-50.

13. Nuti F, Krausz C. Gene polymorphisms/mutations relevant to abnormal spermatogenesis. Reprod Biomed Online 2008;16:50413.

14. Nair RR, Khanna A, Singh R, Singh K. Association of maternal and fetal MTHFR A1298C polymorphism with the risk of pregnancy loss: a study of an Indian population and a meta-analysis. Fertil Steril 2013;99:1311-8.e4.

15. Schroecksnadel K, Frick B, Wirleitner B, Schennach H, Fuchs D. Homocysteine accumulates in supernatants of stimulated human peripheral blood mononuclear cells. Clin Exp Immunol 2003;134:53-6.

16. Park CW, Han AR, Kwak-Kim J, Park SY, Han JY, Koong MK, et al. The role of methylenetetrahydrofolate reductase C677T polymorphism on the peripheral blood natural killer cell proportion in women with unexplained recurrent miscarriages. Clin Exp Reprod Med 2011;38:168-73.

17. Rai V. Methylenetetrahydrofolate reductase C677T polymorphism and recurrent pregnancy loss risk in asian population: a meta-analysis. Indian J Clin Biochem 2016;31:402-13.

18. Zhu Q, Chen Y, Dai J, Wang B, Liu M, Wang Y, et al. Methylenetetrahydrofolate reductase polymorphisms at 3'-untranslated region are associated with susceptibility to preterm birth. Transl
Pediatr 2015;4:57-62.

19. Jeon YJ, Kim JW, Park HM, Kim JO, Jang HG, Oh J, et al. Genetic variants in 3'-UTRs of methylenetetrahydrofolate reductase (MTHFR) predict colorectal cancer susceptibility in Koreans. Sci Rep 2015;5:11006.

20. Bartel DP. MicroRNAs: genomics, biogenesis, mechanism, and function. Cell 2004;116:281-97.

21. Lachapelle MH, Miron P, Hemmings R, Roy DC. Endometrial T, B, and NK cells in patients with recurrent spontaneous abortion: altered profile and pregnancy outcome. J Immunol 1996;156: 4027-34.

22. Fukui A, Fujii S, Yamaguchi E, Kimura H, Sato S, Saito Y. Natural killer cell subpopulations and cytotoxicity for infertile patients undergoing in vitro fertilization. Am J Reprod Immunol 1999;41: 413-22.

23. Tabiasco J, Rabot M, Aguerre-Girr M, El Costa H, Berrebi A, Parant $\mathrm{O}$, et al. Human decidual NK cells: unique phenotype and functional properties--a review. Placenta 2006;27 Suppl A:S34-9.

24. Koopman LA, Kopcow HD, Rybalov B, Boyson JE, Orange JS, Schatz $F$, et al. Human decidual natural killer cells are a unique NK cell subset with immunomodulatory potential. J Exp Med 2003;198:1201-12.

25. Hanna J, Goldman-Wohl D, Hamani Y, Avraham I, Greenfield C, Natanson-Yaron S, et al. Decidual NK cells regulate key developmental processes at the human fetal-maternal interface. Nat Med 2006;12:1065-74.

26. Barch MJ, Knutsen T, Spurbeck JL. The AGT cytogenetics laboratory manual. 3rd ed. Philadelphia: Lippincott-Raven; 1997.

27. Rosen HR, Doherty DG, Madrigal-Estebas L, O'Farrelly C, GoldenMason L. Pretransplantation CD56(+) innate lymphocyte populations associated with severity of hepatitis $C$ virus recurrence. Liver Transpl 2008;14:31-40.

28. Carbone T, Nasorri F, Pennino D, Eyerich K, Foerster S, Cifaldi L, et al. D56highCD16-CD62L- NK cells accumulate in allergic contact dermatitis and contribute to the expression of allergic responses. J Immunol 2010;184:1102-10.

29. Kwak JY, Kwak FM, Ainbinder SW, Ruiz AM, Beer AE. Elevated peripheral blood natural killer cells are effectively downregulated by immunoglobulin $G$ infusion in women with recurrent spontaneous abortions. Am J Reprod Immunol 1996;35:363-9.

30. Lee SK, Na BJ, Kim JY, Hur SE, Lee M, Gilman-Sachs A, et al. Determination of clinical cellular immune markers in women with recurrent pregnancy loss. Am J Reprod Immunol 2013;70:398-411.

31. Wu C, Gong Y, Sun A, Zhang Y, Zhang C, Zhang W, et al. The human MTHFR rs4846049 polymorphism increases coronary heart disease risk through modifying miRNA binding. Nutr Metab Cardiovasc Dis 2013;23:693-8. 